\title{
Preludes and fugues for piano in the polyphonic works of Chinese composers
}

\author{
Marianna Chernyavska* \\ Zhang Mengzhe** \\ * Corresponding Author, Ph.D. in musicology, Professor of the Department of Special Piano, Kharkiv \\ National I. P. Kotlyarevsky University of Arts, Ukraine. Address: 10 Kholodnohirska Street, Apt. \\ 183. Kharkiv, Ukraine. https://orcid.org/0000-0002-8379-5536; e-Mail: pianokisa@gmail.com. \\ ** Graduate student of the Department of Interpretology and Analysis of Music, Kharkiv I.P. \\ Kotlyarevsky National University of Arts, China. Address: 50 Tselinogradskaya Street. Kharkiv, \\ Ukraine. https://orcid.org/0000-0003-0988-4263; e-Mail:764735303@qq.com.
}

DOI 10.12975/rastmd.2021931 Submitted October 10, 2021 Accepted December 19, 2021

\begin{abstract}
The objective of the study is to identify the role of the small cycle "Prelude and Fugue" in the piano work of Chinese composers in the field of polyphonic genres, to consider the most striking examples of Preludes and fugues from the standpoint of the interpretation of the genre, the use of musical and expressive means, performing implementation. The research methodology is based on an integrated approach that combines theoretical methods with historical ones, reflecting the evolution of musical thinking. All the issues raised in the process of analyzing fugues are considered in combination with certain artistic tasks generated by the internal content of the work. The analysis of piano Preludes and fugues by composers Ding Shande, Chen Zhi Ming, Wang Lisan, Rao Yu Yang, Lin Hua made it possible to deduce a number of features of their construction and musical language in connection with the issues of form formation, thematic content, tonal lighting, rhythmic features, polyphonic ways of development and qualitative transformation of the material. In the Preludes and fugues of Chinese composers, essential and fundamental factors come into close interaction: deep connections coming from the polyphony of the "strict style" and the fugues of J. S. Bach, the organic implementation of the principles of national folk melos and the polyphonic warehouse of instrumental folklore, innovation rooted in the incessant search for new means of expression and enrichment of the musical language. The latter is determined by the content of the composers' music, its fullness with a variety of moods, experiences, reflections on the meaning of human life, about our complex century, saturated with the most serious events and phenomena. In the fusion of these qualities, a subjective moment plays a primary role: the uniqueness of the composer's creative individuality, which leaves a certain imprint on all the compositions - in close-up and in detail.
\end{abstract}

\section{Keywords}

Chinese piano music, polyphony, Prelude and fugue, pentatonic scale, performance

\section{Introduction}

Fugue and other polyphonic genres (inventions, program polyphonic pieces, suites in the polyphonic style, small and large polyphonic cycles of program and non-program type, etc.) have become widespread in the piano works of Chinese composers. A fugue as the highest form of the development of polyphony in music was most vividly embodied in the small cycle "Prelude and fugue".

To date, Chinese composers Ding Shande, Chen Zhi Ming, Wang Lisan, Lin Xua, Huang An-Lun, etc. have created a 
considerable number of piano works with a similar genre name. The inheritance of the European genre of Prelude and fugue laid down by J. S. Bach reflects the main trends of the piano creativity of Chinese composers in mastering polyphony, namely, an active comprehension of European traditions and the purposeful use of national folk art, an individual interpretation of the genre and style of the musician.

However, in modern musicology, the genre of the small cycle "Prelude and Fugue" in the piano works of Chinese composers has not become the subject of special consideration. If the fugues written in Europe in various stylistic epochs are quite well studied (Chapin, K., 2010; Mann, A., 1971; 1987; McGahie, D. P., 2006; Pesic, P., 2017; Williams, P., 2003 etc.), then the fugues based on pentatonic have been studied very little, which prevents their introduction into the world performing practice. Currently, Chinese polyphonic works for piano represent a significant layer of the national piano repertoire.

\section{Literature Review}

Despite the fact that Chinese researchers are actively studying the national piano music of Bai Ye (2018), Fan Zuyin (2004), Peng Cheng (2006), Sun Wei-bo (2006), $\mathrm{Wu} \mathrm{Na}$ (2009) there are no special studies in modern musicology devoted to the study of the small cycle "Prelude and Fugue" in the piano works of Chinese composers. In China itself, this problem also requires comprehensive in-depth coverage. Modern scientific developments in the field of polyphony are focused on the study of this phenomenon in the field of mathematics and physics (Li Xiaoquan, 2018; Igarashi
Yuki, 2013; Weiwei Zhang, 2016). The only study where only some preludes and fugues of Chinese composers are used as material is the dissertation of Sun Weibo (2006). However, the author pays special attention to the peculiarities of the interpretations of the small and large polyphonic cycles, only mentioning a few samples of Preludes and Fugues for piano. All of the above indicates the need for research devoted directly to the small cycle "Prelude and Fugue" in the piano works of Chinese composers. This would contribute to solving a number of topical issues of modern musicology.

The objective of the study is to identify the role of the small cycle "Prelude and Fugue" in the piano work of Chinese composers in the field of polyphonic genres.

\section{Problem of Study}

Problem of Study is to consider the most striking examples of Preludes and fugues from the standpoint of the interpretation of the genre, the use of musical and expressive means, performing implementation. To accomplish this task, a study was undertaken of the "Preludes and Fugues" for Piano in the works of the composers Ding Shande (Story 1), Chen Zhi Ming (Story 2), Wang Lisan (Story 3), Rao Yu Yang and Lin Xua (Story 4). Each of the sections is intended to highlight the following subproblems:

- to reveal the features of the polyphonic thinking of Chinese composers - the construction and musical language associated with the issues of form formation, thematic content, tonal lighting, rhythmic features, polyphonic methods of development and qualitative transformation of the material; 
- to consider the innovation of the modal synthesis in the works under consideration, which is manifested in the interaction of the yun-gong-diao system with the major-minor system and modern Western European compositional techniques;

- to reveal the features of the piano style of each composer, to reveal its national characteristics, connection with the traditions of European pianism, to determine the main range of musical expression means, the nature and methods of pianistic presentation.

\section{Methods}

The research methodology is based on an integrated approach that combines theoretical methods with historical ones, reflecting the evolution of musical thinking. All the issues raised in the process of analyzing fugues are considered in combination with certain artistic tasks generated by the internal content of the work.

\section{Research Model}

The research model is based on the interconnection of three cognitive levels: thecreativeprocess, musicological analysis, and methodological comprehension (Kulapina, O., 2014, p: 58).

\section{Data Collection Tools-Documents}

The study of musical material in this article is based on:

- genre-style analysis, as well as on the theoretical positions of musicologists (Chapin, K., 2010; Mann, A., 1971; 1987; McGahie, D. P., 2006; Pesic, P., 2017; Williams, P., 2003);

- issues of studying polyphony (i.e. many voices) in Chinese musical folklore (Fan Zuyin, 2004; Li Hong, 2015)

- specifics of integration processes in Chinese piano art (Bai Ye, 2018),

- features of the fret organization of Chinese piano music (Peng Cheng, 2006);

- research of professional composer creativity of Chinese creators (Sun Weibo, 2006; Wu Na, 2009);

- questions of performance implementations based on the development of the performing principles of polyphony Ying Jiang (2019).

\section{Data Analysis}

The research material is: " 4 preludes and fugues" op. 29, Ding Shande; «13 preludes and fugues" Chen Zhi Ming; "Tashan suite" ("5 Preludes and fugues") Wang Lisan; "Prelude and Fugue" Rao Yu Yang; "3 Preludes and fugues" Lin Xua, etc.

\section{Process}

In the process of research, the article uses the following methods:

- historical-typological - contributes to the building of historical ties and continuity of various links in the field of Chinese musical art;

- systemic - ensures the interaction of functional and structural characteristics of the studied phenomena in the field of genre-style interpretation of Chinese piano works;

- philosophical and aesthetic - allows you to comprehend the worldview positions and creative evolution of Chinese composers; 
- genre-style - allows to reveal the composer's interpretation of the piano works of the small cycle "prelude and fugue";

- structural and functional, used in compositional dramatic and performing analysis of works;

- intonation analysis - to determine the ways of updating a specific musical text;

- interpretational - focuses on the problems of adequate reproduction of the composer's text and the national sound ideal in performing practice;

- comparative analysis - allows you to identify similar and different in the interpretation of the small cycle «Prelude and Fugue» in the piano work of Chinese composers;

- culturological - used to substantiate the mental foundations of Chinese piano art, as well as to identify the types of implementations of folklore genesis in the language and form of works by composers.

\section{Results and Discussion}

An important feature of the formation of the Chinese school of composition, along with mastering the European experience of compositional technique, was the reliance on Chinese traditional music. The main mode of the piano compositions of Chinese composers was the pentatonism - the traditional mode of the Chinese musical system. The pentatonism five steps are the basis of all Chinese tones, including six-, seven -, eight-and nine-step sound orders. You can get acquainted with the complex multilevel tonal system of Chinese tones by reading the book by the Chinese theorist Peng Cheng "The Chinese traditional tonal system and its application in the twentieth century" (2006).

Story 1. Ding Shande: the first experience of composing "Preludes and Fugues"

The adoption of the fugue in Chinese music is a very curious and contradictory process; the form that developed in Western European musical art did not immediately adapt to the originality of Chinese music. Fugal forms were introduced into Chinese piano music by one of its founders, Ding Shande (1911-1995). In his polyphonic works, certain elements were revealed that were further developed and affected the thematism of fugues, the form of the whole; they proceeded from the specificity of the ways of developing the material inherent in Chinese folk song, the composition of its melos.

Ding Shande creatively developed the traditional features of classical polyphony based on the stylistic features of Chinese folk music. The outstanding Chinese composer introduced significantly new formative qualities into polyphonic works associated with the development of the laws of traditional national musical art. On the basis of the fugue, the composer for the first time managed to create a polyphonic form that vividly and organically embodies national specifics. The artistic fusion of classical polyphony and native national art became the basis of stylistic synthesis in the polyphonic works of Ding Shande and determined the national specifics of the polyphonic form.

One of the most important aspects of Ding Shande's polyphonic creativity is 
the problem of traditions and innovation, which is closely related to the composer's "orientation" to the most important polyphonic principles, styles of composers of the past and present, and his search for new intonation and compositional forms, genre strokes. The formation of the style of the Chinese composer was particularly influenced by the work of the great polyphonist J. S. Bach. The national roots of the polyphonic style of Ding Shande are connected with the refraction of the characteristic trends of modern music, including the linearity of orchestral thinking, which is more or less characteristic of most of the greatest composers of the XX century. The composer has particularly well and comprehensively developed polymelodic tendencies associated not only with the creative development of the traditions of the past, but also with the traditions of Chinese folk music. As a result, there is a complex tonal complex with elements of the traditional yun-gongdiao tonal system, which has existed in China for many centuries and has not lost its significance in the twentieth century.

Despite the external similarity of the tonal properties of the folk music of China and the Slavic peoples, the principles of the melodic organization of these cultures are fundamentally different, and this shows the truly inexhaustible possibilities of the diatonic forms of the sound system of melody and harmony. Some tones of Chinese folk music even at first glance coincide with European tones in construction, however, they cannot be identified, since they are dominated by different intra-tonal ratios. For example, if in European tones the seventh step is allowed in the first, then in Chinese music the seventh step is allowed in the sixth.

A vivid manifestation of the polyphonic thinking of Ding Shande (1911-1995) was his piano cycle "4 Preludes and fugues" op. 29. Turning to Bach's construction of the small polyphonic cycle "Prelude and fugue", the composer continued the improvisational type of musical thinking characteristic of Bach, trying to present the listener with a "laboratory" of his creative thought. The fugue in the work of Ding Shande is always an innovative search.

The composer's bold innovation was the refusal to combine the small cycle "Prelude and fugue" with one tonality. According to the researcher $\mathrm{Wu} \mathrm{Na}$ "unusual tonal system of preludes and fugues of Ding Shande reminiscent the tonal convergence of major-minor from Hindemith, polysynthesism of his tonality is consistently stood at Ding Shande principle of communication of preludes and fugues through the final tone that is either the original sound of the next song, or its central tone, like when interludes and fugues, as well as fugues and subsequent interludes from Hindemith" (Wu Na, 2009, p: 21).

Despite the difference in tonalities associated with the compositional structure of the cycle "Preludes and fugues", both piano pieces constitute an independent polyphonic dilogy. A similar compositional scheme is generally preserved in all four preludes and fugues of Ding Shande. In addition, the composer provides each piece with a program. In this way, it strengthens the principle of figurative-dramatic unfolding within a mini-cycle. The idea of contrasting "parts of subcycles, as well as the idea of the connection 
of fugues and subsequent preludes, consistently implemented in the Ding Shande cycle" (ibid.), also reveals close ties with the "Ludus tonalis" by P. Hindemith. The analogy with the music of the outstanding German polyphonist is also indicated by "the application of the modulation principle of constructing preludes and fugues, which is manifested in Ding Shande in the change of the central tone, as well as in the method of modulating (changing the central tone) through the transposition of large fragments of the form" (ibid.).

Each piece of the small cycle reflects a certain internal state. Thus, the composer calls Prelude No. 1 "Contemplation", tuning in to a contemplative mood. Fugue No. 1 "Rapture" is built on the intonations of folk dance, has a clear pentatonic basis. The figurative sphere in Prelude and Fugue No. 2 is sharply polar. Prelude No. 2 "Sadness" is based on elements of mournful folk songs, where the melody is interrupted by sobs. Fugue No. 2 "Joy" is written on the basis of the ancient Chinese tone f-zhi with pronounced tonic and dominant steps ( $f$ and $c$ ), giving the theme of the fugue a characteristic tonal color and stability.

Prelude No. 3 "Joyful Jumps" fully reflects the title of the piece. It is based on a variable pairwise movement of the eighths in each hand. Sometimes this movement converges. The fast pace of Vivace emphasizes the impetuosity of movement. In fugue No. 3, which is called "The Subsequent statement", the ancient Chinese tone B-zhi is used.

Prelude No. 4 "Excitement" is based on dance rhythms: a polyphonic combination of the ostinato movement of the fifth intonation in the left hand and the Chinese folk bamboo flute playing in the right. Fugue No. 4 "Rejoicing" continues the figurative structure of the prelude. The innovation of this fugue was manifested primarily in the tonal plan of the theme itself. In the first two bars, it is presented in tone c-gong. Despite the fact that only four sounds of the tonality c-gong are used in this fragment of the theme and it ends on the third tone of the tone, the position of the tonic and dominant is very stable. Next, the theme modulates into the tonality a-gong and, finally, into fis-yu (the tonality of the tonal system a-gong). Thus, the tonal plan of the theme is very whimsical: c-gong - a-gong - fis-yu.

It should be noted that the prelude of Ding Shande is the most important link in the musical and dramatic narration of the polyphonic mini-cycle, it is in the prelude that the subjective factor is concentrated. In the fugues, the composer boldly uses ancient Chinese tones, in his small-sized fugues, he is an example of the composer's revival of the structure of the classical polyphonic form, enriched with elements of the Chinese mode-tonal system and folk music. Thus, the task of the fugue for Ding Shande is not only to combine the national with the classical polyphonic form, but also to introduce a new technique of compositional writing.

\section{Story 2. Chen Zhi Ming: a synthesis of national traditions and modern techniques of composer writing} An integral feature of the piano work of Chen Zhi Ming (born in 1927), the author of many chamber, string, and vocal works, is the polyphony of thinking. The polyphony in his piano 
compositions is directly connected with the most essential and peculiar features of the composer's style. The composer's interest in polyphony was quite active. This is confirmed by a number of theoretical works of Chen Zhi Ming devoted to polyphony - "Compositional features of the fugue", "Fundamentals of polyphonic composition", "Thoughts about polyphony".

Chen Zhi Ming's appeal to polyphony is not accidental. The composer studied a lot of pre-Bach polyphony. It is quite obvious that Chen Zhi Ming's polyphonic thinking was formed under the influence of Bach, Handel, Taneyev, Shostakovich, as well as through the implementation of the laws of folk and national music. The most important aspect of the composer's polyphonic style is his implementation of classical polyphonic forms, in particular, its highest form - the fugue. Chen Zhi Ming inherited many characteristic features of the polyphonic thinking of Hindemith, Shostakovich, Shchedrincomposers who played a significant artistic and historical role in the process of reviving and rethinking the fugue.

One of the important issues is Chen Zhi Ming's creative development of the stylistic features of Chinese music of the oral tradition, in connection with which the polyphonic forms in the composer's work must also be considered within the framework of the problem of the correlation of the national and international. This perspective creates a rich basis for theoretical analysis, helps to reveal the artistic image of an outstanding Chinese composer and his place in modern musical art.

\section{Chen Zhi Ming's piano cycle “13}

Preludes and fugues" is the composer's highest achievement in the field of this polyphonic form, implemented in a complete polyphonic cycle. This cycle has become a concentrated embodiment of the polyphonic "orientation" manifested from the very early stages of the composer's creative biography, his desire for a polyphonic genre, form, and style. Thus, Chen Ji Ming once again emphasized the viability of not only the fugue itself, but also the cyclicity that arose on its basis.

Being an inspired and bold development of the Bach traditions, the cycle " 13 Preludes and fugues" by Chen Zhi Ming is at the same time quite innovative in relation to them. In addition, the cycle opens a new stage of the composer's own piano style, reveals new aspects of his piano language and pianism, significantly enriches and expands their capabilities. Hence the peculiarities of this polyphonic cycle - versatility, on the one hand, perfection and completeness, on the other.

Despite all the continuity, Chen Zhi Ming's piano cycle is deeply individual and contains many new solutions of polyphonic technique and polyphonic cyclicity. If the composer does not try to introduce significantly new touches directly into the structural composition of the fugue, innovation is noticeably revealed in the construction of the entire cycle, which for the first time is due to the figurative-dramatic concept. So, unlike other cycles of this kind, where the ratio of tonalities was programmed, invariably, ordered, in the cycle of the Chinese composer, the logic of figurative and dramatic development dictates the tonal plan. Hence, there is a lack of strict 
interval consistency in the following of the fugue tonalities. In addition, within the cycle, Chen Zhi Ming does not separate the prelude and fugue. The fugue usually begins after a pause and fermata, continuing the prelude.

In "13 Preludes and fugues", Chen Zhi Ming masterfully applies the synthesis of the dodecaphone technique of compositional writing, the principles of polytonality and polytonality, which are firmly entrenched in the European music of the twentieth century with the peculiarities of Chinese music. The composer uses a variety of methods of polyphonic technique, while achieving such naturalness and expressiveness, which, at first glance, is incompatible with solving such complex technical problems.

The composer draws a lot of bright, diverse, memorable images in his cycle. For example, in Prelude No. 1, choral imagery dominates. The music is concentrated, epically concentrated. The thematism of the fugue, which begins inside the prelude, like many other fugues of this cycle, is based on a folklore basis. The theme of the song character begins its unhurried development. With the appearance of the second theme in the fugue, a new phase of the image development begins. At the culmination point of the fugue's development, both themes begin to sound in parallel. In the last Allargando joint event, the first theme sounds in magnification, emphasizing the monumentality and grandeur in the development of the image.

Prelude No. 2 is characterized by images of deep philosophical reflection. The fugue built on the progressive movement of broken intervals, contrasts the prelude and presents a bright, incendiary, virtuoso piece. The Prelude and fugue No. 3 are based on a pentatonic tone. While the prelude vividly demonstrates the coloristic possibilities of the piano based on the sound of the pentatonism, then the fugue tends more to folk song and dance intonations.

Prelude and fugue No. 10 have pronounced national features. The theme of the fugue is written in the tonality a-yu. The structure of this tone basically corresponds to the structure of the diatonic minor. The composer designates the functions of the tonic and dominant very carefully, giving the theme not only a national flavor, but also preserving its pronounced minor coloring.

While in the first preludes and fugues 12 non-repeating sounds obey a certain tonic, to which the music comes at the end of the work, the tonal gravitations are gradually increasingly destroyed, almost to the point of complete disappearance. In combination with elements of ancient Chinese tones, the tonal characteristic becomes more and more uncertain, forming a certain new reality, vividly demonstrating the composer's innovative findings.

"13 Preludes and fugues" were the result of a whole period of Chen Zhi Ming's creative activity. Updating the old polyphonic traditions, Chen Zhi Ming created an original polyphonic cycle by means of expressive means, in which the composer's tendency to conciseness and refinement of the musical language found concentrated expression. 
Story 3. Wang Lisan - author of the Chinese "Well-Tempered Clavier"

In 1982, the composer Wang Lisan created the "Tashan Suite", consisting of five "Preludes and fugues". This work was awarded the first prize at the Art Competition of Literature and Arts of Heilongjiang Province. In this work, all the modes of pentatonics were presented, and other "signs of the national originality of the interpretation of the genre, the most important indicators of which are: the program type of polyphonic composition; the concreteness of the figurativesemantic system (as a projection of the principle of theater-centrism on the field of musical thinking); the national identification of thematism (thanks to the pentatonic-tonal basis of intonation)" (Sun Wei-bo, 2006, p: 6).

In the "Tashan suite" you can observe a rare combination of musical programming, national color and modern composition techniques. In all five preludes and fugues, the composer uses the pentatonic fret of the people of the Chinese province of Hanshui, each small cycle is supplemented with a text preface, where explanations are given for a better understanding of the music. Each of the five preludes and fugues has a title and a poetic preamble, the prelude and fugue of each cycle are performed attaca, without the traditional break: 1. Prelude and fugue in fis-shang: "Calligraphy and Qin" (Pentatonism e); 2. Prelude and fugue in a-jue: "Geometric pattern" (pentatonism c); 3. Prelude and fugue in as-zhi : "Song of the Earth" (pentatonism des); 4. Prelude and fugue in g-yu: "Folk Toy" (pentatonism es); 5. Prelude and fugue in f-gong: "Mountain Village" (pentatonism $\mathrm{f}$ ).

Researcher Bai Ye compares this cycle of
Preludes and Fugues, covering all the keys of the pentatonic scale, with the "WellTempered Clavier" by J.S. Bach: "As the great J. S. Bach seized the whole system of major and minor tones, Wang Lisan bethought to change the specific system of Chinese pentatonic modes in the same form of 'little cycle'. The orientation on national principles of musical pitch organization, the reference to national melos, texture-timbre and performing instrumental methods, the sense of musical time, peculiar for the different regions of the country, the principles of form making did not hamper the assimilation of the difficult polyphonic form" (Bai Ye, 2018, p: 141).

In the preface to the first Prelude and fugue, Wang Lisan writes: "The Prelude 'Calligraphy' uses musical notation as a canvas, and the calligrapher writes on it, sometimes barely touching, holding his breath, then with excitement and strength, excitedly following the figures of snakes and dragons created by him" (Wei Tingge ed., 1998, p: 23). "Qin" is a three-voice fugue, its theme is presented in two-octave doubling, imitating the sounds of guqin, the accompanying parts have unprecedented transformations, similar to the sluggish qin sounds.

The second Prelude and fugue in a, "Geometric Pattern" is more abstract, but sometimes pictures of the vast expanses of Hunan appear through its abstraction, and the rhythm and size resemble the folk motif of Huagu ("Flower and Drum"). Music uses multiple modulations, like an everchanging pattern. The fugue begins from afar in a grotesque refraction.

The third Prelude and fugue "Song of the 
Earth" is written with great feeling and is full of depth - the composer's favorite. The prelude begins at the very edge of the keyboard, marked pp, as if the patient Earth is singing a song in a low voice. The left hand repeatedly plays the established descending tones, possibly personifying the roots deeply anchored in the ground. The rhythm contains the sounds of a folk song from Xiabei Province. This is followed by a double fugue.

In the "Folk Toy", a special movement is transmitted, creating a local sound color. The prelude uses sixteen tones and note clusters, evoking associations with many different children's toys that create a children's fantasy world. The fugue has some specific features, first there is an anti-compound, then a theme, and again an anti-compound, which becomes the answer. The cycle ends with "Mountain Village" - a joyful piece that carries the energy of dance. The melody and rhythm are reminiscent of folk songs of the southwestern small nationalities of China.

Thus, it is difficult to overestimate the importance of the appearance of Wang Lisan's "Tashan suite" in Chinese music, "five Preludes and fugues, united into one unit, acquire meaning of the socalled artistic-esthetical manifest by outgrowing the meaning of artistic experiment and could serve as a bright example of integration processes in Chinese music of the last third of the XX century" (Bai Ye, 2018, p: 141-142).

\section{Story 4. National awareness of fugue in the works of Rao Yu Yang and Lin Hua}

Many Chinese composers knowing the Western European major-minor fret system write music in accordance with the strict Chinese tradition. The prelude and fugue of Rao Yu Yang's polyphonic cycle "Lyrics" is also written on the basis of the tone b-zhi. We can already see the composer's brilliant mastery of the technique of polyphonic writing in the prelude, where polyharmonic means are used in combination with the polyphony of layers. Rao Yu Yang's development of the rich metrorhythmic basis of Chinese musical folklore is diverse. The bold variation of the rhythmic and structural traditions of folk music often leads to the fact that folk traditions turn into the author's own finds.

The whole prelude is imbued with a sense of improvisational presentation of the material, coming from the creativity of folk storytellers-shoshuds, the traditions of performing on Huqing and Zheng. The feeling of improvisationality should be comprehended with the help of the most subtle intonation nuances in articulation, minute changes in agogy. In the arsenal of the author's tools are the mastery of the rhythms developed by the people, the knowledge "from within" of folk genres, their specifics. The composer finds sounds that resemble the timbres of various folk instruments. The fugue is based on speech intonations.

Lin Hua's polyphonic cycle "3 Preludes and fugues" demonstrates a multifaceted figurative content. The composer expressed her attitude to the tonal organization of music, in the field of which new complex experimental systems have repeatedly appeared, emphasizing the importance and viability of the tonal factor.

Prelude No. 1 draws a majestic epic 
picture with powerful sound strokes. In its philosophical and tragic orientation, the prelude resembles an excited and at the same time severe dramatic monologue of the author. The figurative sphere of fugue No. 1 "Debility" is directly opposite to the image of the prelude. The connection of the musical language of the fugue with the Chinese folk melody is characterized by a great saturation of the composer's melody with various typical intonations of Chinese folk melos.

The synthesis of artistically multidirectional methods and principles of shaping, the combination of opposite images, contradictory methods of utterance and in general is characteristic for Lin Hua. It is one of the ways to display the acute conflict of the surrounding world, an aesthetic expression of the unity of its contradictory diversity, the complexity of internal connections. Hence the composer's tendency to express a contrasting "polyphony" of images and feelings, a polyphonic combination of a high intensity of emotions with a deep pathos of thoughts.

Of great importance in the knowledge of the essence of the melodic process are the tonal patterns on the basis of which this process develops. The composer's palette of tonal colors is very extensive. First of all, it should be noted the successful coexistence of the Chinese folk-tonal systems with the Western European major-minor. In many cases, folk modes in the composer's music are significantly enriched and receive a new kind of interpretation. But, as a rule, the composer's boldest interpretation of certain fret patterns is based on a folk "core" and this largely contributes to the fact that very complex forms of musical development in the composer's works are easily perceived and accessible to the broad masses of listeners.

Prelude No. 2 is a piece of an etude character, built on the fluid movement of the sixteenth in both hands. Here the pianist faces certain technical difficulties. The above clarifies and emphasizes the main point: all the means of musical expressiveness used by the composer in creating the thematism of fugues are aimed at revealing their national warehouse in the most relief form.

The theme of fugue No. 2 "Coldbloodedness" contains intonational commonality with the themes of folk songs, recitative lamentations and lamentations (intonation of a sigh and a groan), majestic or epic chants. It is precisely this song-drawn-out character that largely stimulates the tendency to a long "slow" character of shaping in this fugue. Here, the form turned out to be the other side of the desire to sing the fugue's thematism as much as possible.

Prelude No. 3 "Big Drum" is the central culmination of the entire polyphonic cycle of Lin Hua. It is an interesting combination of Chinese musical folklore and the passacaglia genre. The prelude consists of a theme and five polyphonic variations on an unchanging bass. The basso ostinato technique was used by ancient masters to express a long stay in the same emotional sphere, often mournful feelings. This prelude is written according to this principle. The intonational content of melodics is the germ from which other elements of the musical language, including polyphony, 
grow. Melodic intonations to a certain extent coordinate the unification of all these elements into a single organic complex of expressive means of a musical work.

The theme of fugue No. 3 "Lightness" resembles instrumental tunes, in particular, folk dance melodies of the Chinese pipe. The innovative search for the composer opened up limitless possibilities for the development of various stylistic trends based on the fundamental principles of national art.

In the work of Lin Hua, there is a national "awareness" of the fugue. Relying on the extensive polyphonic experience of her predecessors, she creates a complete sample of the fugue, or rather, the traditional polyphonic dilogy-prelude and fugue) based on the organic interaction of the stylistic features of Chinese folk music and polyphonic techniques.

\section{Conclusions}

The analysis of piano Preludes and fugues by composers Ding Shande, Chen Zhi Ming, Wang Lisan, Rao Yu Yang, Lin Hua made it possible to deduce a number of features of their construction and musical language in connection with the issues of form formation, thematic content, tonal lighting, rhythmic features, polyphonic ways of development and qualitative transformation of the material.

In the Preludes and fugues of Chinese composers, essential and fundamental factors come into close interaction: deep connections coming from the polyphony of the "strict style" and the fugues of J. S. Bach, the organic implementation of the principles of national folk melos and the polyphonic warehouse of instrumental folklore, innovation rooted in the incessant search for new means of expression and enrichment of the musical language. The latter is determined by the content of the composers' music, its fullness with a variety of moods, experiences, reflections on the meaning of human life, about our complex century, saturated with the most serious events and phenomena.

In the fusion of these qualities, a subjective moment plays a primary role: the uniqueness of the composer's creative individuality, which leaves a certain imprint on all the compositions - in close-up and in detail.

Most composers demonstrate in Preludes and fugues the close connection of the Chinese folk-tonal systems with the Western European major-minor. In " 13 Preludes and fugues", Chen Zhi Ming masterfully applies the synthesis of the dodecaphonic technique of compositional writing, the principles of polytonality and polymodality. The innovation of the composers Ding Shande, Chen Zhi Ming, Lin Hua was the refusal to combine the small cycle "Prelude and fugue" with one tone.

The composer Wang Lisan, on the contrary, created a kind of Chinese "Well-Tempered Clavier" on the national material (Bai Ye, 2018, p: 141). Almost all Preludes and fugues by other composers, with the exception of " 13 Preludes and fugues" by Chen Zhi Ming, also have program names. All fugues considered in small cycles structurally correspond to the division generally accepted in Western European music into exposition, elaboration, reprise; or-exposition and free part (with or without reprise). 
Chinese composers, creatively mastering and rethinking the experience of Western polyphonists, created the art of a new polyphony, saturating it with national features, firmly linking it with the origins of Chinese national music, giving polyphonic music a new content, and partly a form. New polyphonic forms and qualitative changes in the ways of using polyphonic methods of developing musical material can be created on the basis of a rich concrete musical material represented by an inexhaustible creative folk genius, the achievements of world music classics and all the subsequent development of Chinese musical culture.

In the works of almost all polyphonic composers, the quintessence of their style is a cycle based on a fugue. The creation of such compositions is not only proof of the inexhaustibility of the possibilities of the fugue, but also proof of a certain sound system, the canonical conditions of writing a certain era. All fugues considered in small cycles structurally correspond to the division generally accepted in Western European music into exposition, elaboration, reprise; or-exposition and free part (with or without reprise). In the fugue, two main trends in mastering polyphony have found a vivid embodiment, namely, an active comprehension of European traditions and the purposeful use of national folk art. The use of pentatonic frets in the construction of fugues and other polyphonic genres has become widespread in China.

\section{Recommendation}

\section{Recommendations for Applicants}

The presented scientific research of Preludes and Fugues in Chinese piano art expands the knowledge of a modern musician in the field of a new pianistic repertoire. The obtained theoretical knowledge also allows you to find the most effective ways to achieve a result in the student's learning process. For musicians - representatives of nonChinese nationality - it is very important to understand the specifics of the national intonation nature, timbres, and techniques of Chinese instruments. The acquired knowledge will influence the choice of the performing means of expressiveness, the development of the skill of auditory development, the ability to hear pitch ratios uncharacteristic for equal temperament of a piano.

\section{Recommendations for Further \\ Research}

The prospect of research is seen in the study of other polyphonic genres in the piano work of Chinese composers.

\section{Limitations of Study}

The compositions considered in the article are successfully used in the educational process of music colleges and academies in China. They are studied as a performing concert repertoire in a special piano class, along with works by J.S. Bach, G.F. Handel, D. Shostakovich, P. Hindemith, and others.

\section{Acknowledgement}

Today, pianism in China has reached a very high level, so the interest of listeners from other countries in Chinese music is growing every year. The piano was the instrument that helped build a cultural bridge between China and the rest of the world. One of the links of such a bridge was the training of Chinese students in Ukraine. These young people come to our country to get a higher level of 
European music education. At the same time, they bring drops of their national culture to Ukraine. For more than ten years at the Department of Special Piano of the Kharkiv I. P. Kotlyarevsky National University of Arts Chinese students and graduate students (one of them - the author of the publication Zhang Mengzhe) study with teachers (one of whom - the author of the publication - Marianna Chernyavska) piano works as Western European, Ukrainian, and Chinese composers. Cognition of a new musical culture, the possibility of expanding the modern pianistic repertoire, new imagery, sound techniques, the study of mental attitudes, philosophical principles, etc. - all this enriches the musician. 


\section{Biodata of Authors}

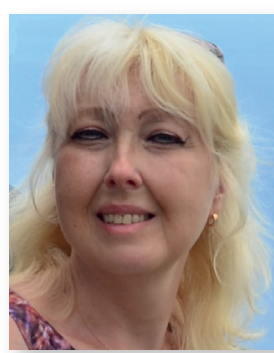

\section{Marianna Chernyavska}

(b. 1967) - Ukrainian pianist, musicologist, teacher, PhD in Arts (2002), professor of the department of special piano at the Kharkiv I.P. Kotlyarevsky National University of Arts (2016). Laureate of the first prize of the H. Eller International piano competition in Tallinn, Estonia (1987). She graduated from the Kharkiv Institute of Arts named I.P. Kotlyarevsky (1990) and then post - training at the Kiev State Conservatory named P.I.Tchaikovsky (1992). Conducts scientific activity, being the author of scientific manuals on the music art more than 40 scientific articles, lectures programs. She takes part in international and national scientific conferences. Among her pupils there are laureates of international competitions as well as the candidates of art (Ph.D.).

\section{Zhang Mengzhe}

(b. 1991) - Chinese pianist, musicologist, researcher of Chinese music. In 2018 she graduated from the magistracy at the Kharkiv I.P.Kotlyarevsky National University of Arts (Ukraine) and entered graduate school with a degree in musical art. Currently, she is a postgraduate student of the Department of Interpretation and Analysis of Music at the Kharkiv I.P.Kotlyarevsky National University of Arts. 


\section{References}

Bai Ye. (2018). Conceptual Models of Chinese Piano Music Integration into the Space of Modern Music. International Review of the Aesthetics and Sociology of Music, Vol. 49, No. 1 (June 2018), pp. 137-148. https://www.jstor.org/ stable/26844635

Chapin, K. (2010). Time and the Keyboard Fugue. 19th-Century Music, Vol. 34, No. 2 (Fall 2010), pp. 186-207 Published by: University of California PressStable URL: http: / / www.jstor.org/stable/10.1525/ ncm.2010.34.2.186.

Fan, Zuyin (2004). Folk musical polyphony of China. Beijing.

Igarashi, Yuki \& Ito, Masashi \& Ito, Akinori. (2013). Evaluation of Sinusoidal Modeling for Polyphonic Music Signal. 2013 Ninth International Conference on Intelligent Information Hiding and Multimedia Signal Processing Publisher: IEEE, Beijing, China, 464-467. DOI: 10.1109/IIH-MSP.2013.121.

Kulapina, O. (2014). Methodology of Musicology in the Context of Higher Music Education: Conceptual Attitudes. Musical art and education. Issue 4, 58-66. https: / / cyberleninka.ru/article/n/metodologiyamuzykoznaniya-v-kontekste-vysshegomuzykalnogoobrazovaniya-ponyatiynyeustanovki

Li, Hong. (2015). The Practice of Integration Guangxi Polyphonic Folk Music into Chorus Singing Teaching for Normal University Students. International Conference on Advanced Education and Management (ICAEM 2015), 488-492.

Li, Xiaoquan \& Yan, Yijun \& Ren,
Jinchang \& Zhao, Huimin \& Zhao, Sophia \& Soraghan, John \& Durrani, Tariq; Liang, Qilian \& Mu, Jiasong \& Jia, Min \& Wang, Wei \& Feng, Xuhong \& Zhang, Baoju, eds. (2018). Knowledge based fundamental and harmonic frequency detection in polyphonic music analysis. Communications, Signal Processing, and Systems. Springer, CHN, 591-599. ISBN 9789811065705.

Mann, A. (ed.) (1971). The study of Counterpoint from Johann Sebastian Bach Fux's Gradus ad Parnassum. W.W.Norton \& Company, New York.

Mann, A. (1987). The Study of Fugue (Dover Book on Musik). Dover publications, New York.

McGahie, D. P. (2006). The choral fugue: A comparative study of style and procedure in works by J. S. Bach and W. A. Mozart. (Abstract of the thesis ... DMA), University of Cincinnati.

Peng, Cheng (2006). The Chinese Traditional Modal System and Its Application in the 20th Century: A Study. Moscow: Moscow State Pedagogical University.

Pesic, P. (2017). Polyphonic Minds: Music of the Hemispheres. The MIT Press Cambridge, Massachusetts, London.

Sun, Wei-bo. (2006). Polyphonic Cycle in the Piano Creativity of Chinese Composers: Tradition and Innovation. (Abstract dissertation. candidate of art history). Belarusian State Academy of Music, Minsk.

Wei, Tingge. ed. (1998). Selection from 
Chinese Classical Music for Piano № 2.

Editors-in-Chif: Wei Tingge, Li Mingjun, Xu Min. ShiDaiWenYi Publishing House, Shanghai.

Williams, P. (2003). The Organ Music of J. S. Bach. Ed. 2. Cambridge U. Press.

Wu, Na. (2009). Ding Shan Te's Piano Music: Combining Chinese National Tradition with Modern Methods of European Writing. (Abstract of the dissertation of a candidate of art history). St. Petersburg N. A. Rimsky-Korsakov State Conservatory. St. Petersburg.

Weiwei, Zhang \& Zhe, Chen \& Fuliang, Yin. (2016). Main melody extraction from polyphonic music based on modified Euclidean algorithm. Applied Acoustics Volume 112, 70-78. https://doi. org/10.1016/j.apacoust.2016.04.023

Ying, Jiang. (2019). Reviving the Beauty of Bach's Music - On the Teaching of Bach's Polyphonic Works. Advances in Social Science, Education and Humanities Research, volume 322 2nd International Seminar on Education Research and Social Science (ISERSS 2019). Series Advances in Social Science, Education and Humanities Research. Atlantis Press, 156-159. https: / /doi.org/10.2991/ iserss-19.2019.41 
